\title{
Critical rigidity of stiffener for increasing shear stability of rectangular plate
}

\author{
A.I. Pritykin*, I.E. Kirillov** \\ *Immanuel Kant Baltic Federal University, A. Nevskogo str. 14,236041, Kaliningrad, Russia and \\ Kaliningrad State Technical University (KGTU), Sovetsky av. 1, 236022, Kaliningrad, Russia, E-mail: prit_alex@mail.ru \\ **Kaliningrad State Technical University (KGTU), Sovetskyav. 1, 236022, Kaliningrad, Russia, E-mail: iljakir@mail.ru \\ cross'ref http://dx.doi.org/10.5755/j01.mech.21.3.9045
}

\section{Introduction}

Efficiency of application of the plate girder with slender web (GSW) is determining with the relatively small thickness of web compare with usual welded beams that give sufficient reducing expense of metal for web and more rational using of it[1, 2].

Experience of using such beams show, that loss of local stability of web take place near supports with typical view of inclined half waves, indicating that reason of buckling is shear deformation (Fig. 1).

Increase loading capacity of web is possible by installation of vertical or inclined stiffeners located near the supports [3-17]. If width of panel between transversal stiffeners is equal to height of web, than we consider stability of square plate otherwise it is necessary to deal with rectangular plate. Namely these two variants are considering in the article to determine efficient sizes of stiffeners for increasing of critical load of the girder web.

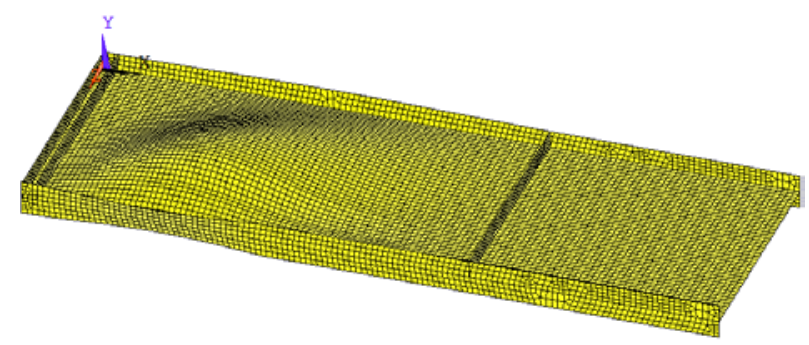

Fig. 1 Form of buckling of GSW near support from the shear deformation

\section{Analysis of plate stability without stiffener}

For analysis of efficiency of stiffeners it was elaborated the computer program for creation of model of rectangular plate, allowing uniform loading of plate on contour with shear forces. The calculations were performed by the finite element method using complex ANSYS. Using any program it is necessary to be convenient in correctness of its work, i.e. in obtaining reliable results. With this aim it was initially calculated stress state of the square and rectangular plates and calculations its shear buckling under two kinds of boundary conditions: clamped one (Fig. 2, a) and simply supported (Fig. 2, b).

For prevention of the plate displacement as rigid whole under calculation by FEM it were used boundary conditions of absence of lineal (in directions of axis $O X$ and $O Y$ ) and angular (rotz) displacements of the plate center. In that case the initial stress state under pure shear of plate is uniform that indicate on correctness of application of boundary conditions and loads.

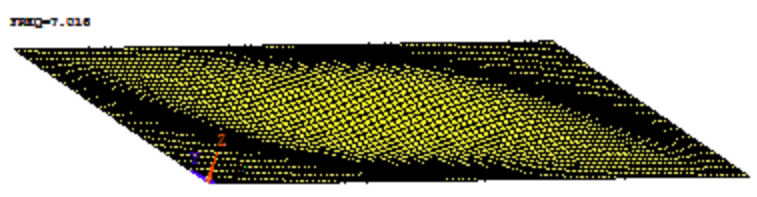

a

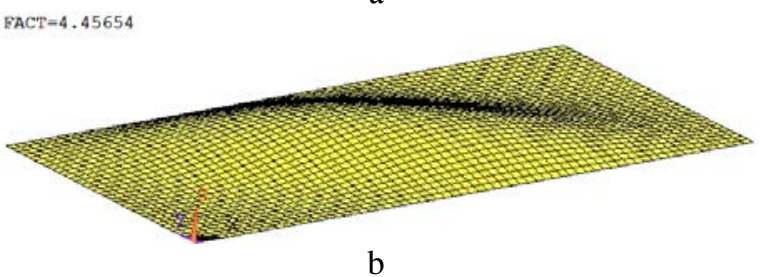

Fig. 2 Forms of buckling of (a) clamped one and (b) simply supported rectangular plate under shear

Estimate reliability of FEM results is possible, using theoretical values for critical shear stresses. In common case dependence for $\tau_{c r}$ takes view:

$$
\tau_{c r}=K \frac{\pi^{2} E t^{2}}{12\left(1-\mu^{2}\right) b^{2}}
$$

here $K$ is numerical coefficient, depending on relation of plate sides $a / b$ and boundary conditions on contour.

For simply supported plate it can be written as [18]:

$$
K=5.34+4(b / a)^{2},
$$

here $b$ is short side of plate. For rectangular plate with dimensions $200 \times 100 \times 0.19 \mathrm{~mm} \quad a=2 b ; K=6.34$ and in accordance with Eq. (1) and Eq. (2) critical stress is determined as:

$$
\tau_{c r}=6.34 \frac{\pi^{2} 2.1 \cdot 10^{5} \cdot 0.19^{2}}{12\left(1-0.3^{2}\right) 100^{2}}=4.34 \mathrm{MPa} .
$$

Calculation with FEM gives $\tau_{c r}=4.45 \mathrm{MPa}$ (Fig. 2, b), i.e. divergence is about $2.5 \%$. The reason of such big divergence is incorrectness of factor $K$ determined on Eq. (2). As it is marked in handbook [3], accuracy value $K=6.47$, substitution of which in Eq. (3) gives value $\tau_{c r}=4.43 \mathrm{MPa}$, practically coinciding with FEM calculation. 

as [18]:

For clamped plate expression for $K$ can be written

$$
K=8.98+5.6(b / a)^{2} .
$$

For rectangular plate $(a=2 b)$ it gives $K=10.38$ and in accordance with Eq. (1) and Eq. (4) value of $\tau_{c r}$ is:

$$
\tau_{c r}=10.38 \frac{\pi^{2} 2.1 \cdot 10^{5} \cdot 0.19^{2}}{12\left(1-0.3^{2}\right) 100^{2}}=7.10 \mathrm{MPa}
$$

Divergence of theoretical value of critical stress with calculated by FEM $\tau_{c r}=7.01 \mathrm{MPa}$ (Fig. 2, a) does not exceed $1.3 \%$.

As it can be seen from Table, obtained results confirm high reliability of program and now it is possible to transfer to determination of influence of stiffener on the plate buckling.

Table

Critical stresses (MPa) of rectangular plates under shear

\begin{tabular}{|l|c|c|c|c|}
\hline \multicolumn{1}{|c|}{ Type of plate } & \multicolumn{2}{c|}{ Rectangular } & \multicolumn{2}{c|}{ Square } \\
\hline Dimensions & \multicolumn{2}{c|}{$200 \times 100 \times 0.19 \mathrm{~mm}$} & \multicolumn{1}{c|}{$100 \times 100 \times 0.19 \mathrm{~mm}$} \\
\hline Boundary conditions & Simple & Clamped & Simple & Clamped \\
\hline$\tau_{c r}^{\text {FEM }}$ & 4.45 & 7.01 & 6.38 & 10.02 \\
\hline$\tau_{c r}^{\text {Theor }}$ & 4.43 & 7.1 & 6.39 & 9.98 \\
\hline Divergence, \% & 0.5 & 1.3 & 0.2 & 0.4 \\
\hline
\end{tabular}

\section{Analysis of plate stability with stiffener}

Under investigation of effect of stiffener it is necessary to get response at three questions: how to install stiffener - vertically or inclined; what are to be dimensions of stiffener; what is the critical rigidity of stiffener? As a critical rigidity of stiffener it can be understand value $E I_{c r}$ with minimum dimensions $h_{r}$ and $t_{r}$, assuring linearity of stiffener during the plate buckling.

Answer the first question is almost known. Installation of stiffener is most effective when it cross buckled surface normally to its location. In case of simply supported rectangular plate (Fig. 3) location of stiffener must be inclined. Calculations with FEM (Fig. 3, a and b) confirm that inclined stiffener under the same parameters of plate is more effective than transversal one.

For answer the second question put attention to SN\&R. Height $h_{r}$ of one side stiffener in accordance with p.8.5.9 [19], is recommended to adopt no less than:

$$
h_{r}=h_{w} / 24+40 \mathrm{~mm} \text {, }
$$

here $h_{w}$ is height of web.

Thickness of stiffener must be not less than:

$$
t_{r}=2 h_{r} \sqrt{R_{y} / E} .
$$

It is necessary to mark that under choice of stiffener dimensions the Eq. (6) is primary and Eq. (7) - secondary, i.e. the bigger height of stiffener the bigger is it thickness. It is clear, that choice of height of stiffener from Eq. (6) does not correspond to parameters of plate: for width of plate $100 \mathrm{~mm}$ stiffener according to Eq. (6) will be bigger $44 \mathrm{~mm}$. Of course for plate with dimensions $200 \times 100 \mathrm{~mm}$ such recommendation is not suitable. It is obvious nonsense, leaking from presence in Eq. (6) the term not depending from parameters of plate. That is why for any plate the height of stiffener according to Eq. (6) will not be less of $40 \mathrm{~mm}$.
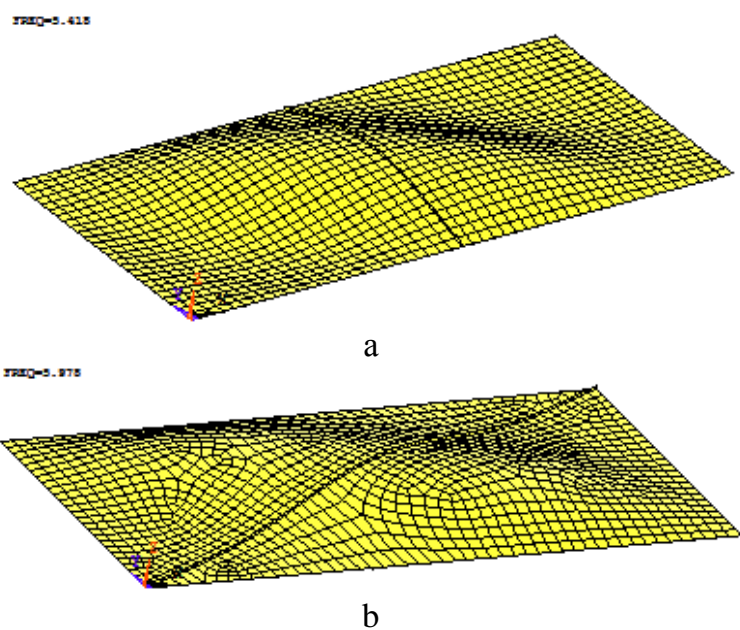

Fig. 3 Critical stresses of simply supported rectangular plate with vertical (a) and inclined (b) stiffener $h \times t=1 \times 0.19 \mathrm{~mm}$

For webs of beams of big sizes (for example, $h_{w}=$ $=1000 \mathrm{~mm}$ ) such recommendation is quite suitable, only it is necessary to restrict field of application the Eq. (6). It is clear that and second Eq. (7) lead to incorrect result. In order to obtain more a equate relation it will be considered stability of clamped and simply supported plate with different stiffeners using FEM. It allows understanding what real sizes of stiffener are to be.

In Eurocode EN 1993-1-5[20] demands to transverse stiffeners, creating rigid support for web, are one of two conditions:

$$
I_{s t} \geq 1.5 h_{w}^{3} t_{w}^{3} / a^{2} \text {, if } a / h_{w} \leq \sqrt{2},
$$

or:

$$
I_{s t} \geq 0.75 h_{w} t_{w}^{3}, \text { if } a / h_{w} \geq \sqrt{2},
$$

here $a$ is width of BFW panel between transverse stiffeners; $h_{w}$ is height of web; $t_{w}$ is thickness of web.

Plate with sides $a / b=2$ is suit to Eq. (8). Substitution in Eq. (8) of moment inertia of stiffener, allow get condition for demanded height of stiffener:

$$
h_{r} \geq 2.08 t_{w} \sqrt[3]{h_{w} / t_{r}} .
$$

If thickness of stiffener is equal to thickness of plate $t_{r}=t_{w}$ then from Eq. (9) we obtain:

$$
h_{r} \geq 2.08 t_{w} \sqrt[3]{\lambda_{w}},
$$

here $\lambda_{w}=h_{w} / t_{w}$ is the web slenderness.

If demand Eq. (10) is not satisfied, then stiffener is flexible. Its real rigidity can be determined by the finite element calculation of the plate stability. 


\section{Critical rigidity of stiffener}

Determine optimal sizes of stiffener are possible if take into account results obtained in work [21]. For rectangular plate such sizes can be find from relation of rigidity of stiffener and plate:

$$
E I / D l_{r}=4.5
$$

here $I=t_{r} h_{r}^{3} / 12$ is moment of inertia of stiffener; $D=E t_{w}^{3} / 12\left(1-\mu^{2}\right)$ is cylindrical rigidity of plate; $l_{r}$ is length of stiffener. After substitution of expressions for $I$ and $D$ in Eq. (11) give:

$$
t_{r} h_{r}^{3}\left(1-\mu^{2}\right) / l_{r} t_{w}^{3} \geq 15
$$

If thickness of stiffener $t_{r}$ is adopted distinct from thick-ness of plate $t_{w}$, then from Eq. (12) with $\mu=0.3$ is possible to express critical height of stiffener as:

$$
h_{r}=1.7 t_{w} \sqrt[3]{l_{r} / t_{r}} .
$$

So far as most rational location of inclined stiffeners $45^{\circ}$, the length of rib need to adopt equal:

$$
l_{r}=h_{w} \sqrt{2} \text {. }
$$

Then substitution Eq. (14) in Eq. (13) give:

$$
h_{r}=1.91 t_{w} \sqrt[3]{h_{w} / t_{r}}
$$

In case of equal thicknesses of plate and rib $t_{r}=t_{w}$ instead of Eq. (15) we get:

$$
h_{r}=1.91 t_{w} \sqrt[3]{\lambda_{w}}
$$

Check up Eq. (16) for plate with sizes $200 \times 100 \times 0.19 \mathrm{~mm}$. Substitution of $h_{w}=100 \mathrm{~mm}$ and $t_{w}=0.19 \mathrm{~mm}$ in Eq. (16) give:

$$
h_{r}=1.91 \cdot 0.19 \sqrt[3]{100 / 0.19}=2.93 \mathrm{~mm},
$$

that is in good correlation with result represented in Fig.4.
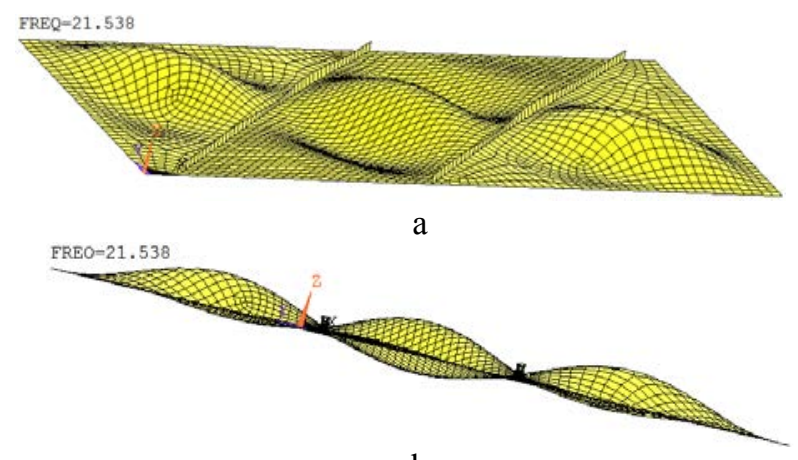

b

Fig. 4 Critical stress of clamped rectangular plate $200 \times 100 \times 0.19 \mathrm{~mm}$ with two stiffeners $2.93 \times 0.19 \mathrm{~mm}(\mathrm{a}, \mathrm{b}-$ different view)

\section{Installation of two stiffeners}

Performed calculations by FEM of clamped plate with two inclined ribs show that on critical load big influence have not only sizes of ribs but their location also (Fig. 5). All ribs of the same size $2.5 \times 0.19 \mathrm{~mm}$, have inclination $45^{\circ}$, but different distance from angle of plate: $x=5,20$ and $40 \mathrm{~mm}$.

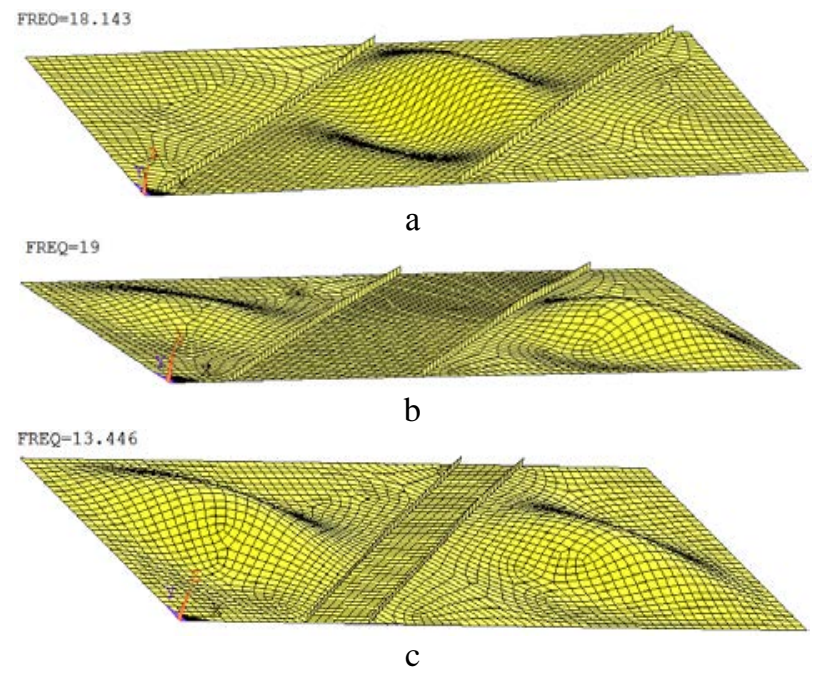

Fig. 5 Critical stresses of clamped plate $200 \times 100 \times 0.19 \mathrm{~mm}$ with different location of ribs: $\mathrm{a}-x=5 \mathrm{~mm}$; $\mathrm{b}-x=$ $=20 \mathrm{~mm} ; \mathrm{c}-x=40 \mathrm{~mm}$

Analysis show (Fig. 6), that transfer of ribs from angle to middle of the plate side initially increase critical load and then reduce it. Practically in all cases optimal location of ribs correspond to distance $x=0.1 b$ ( $b$ is width of plate).

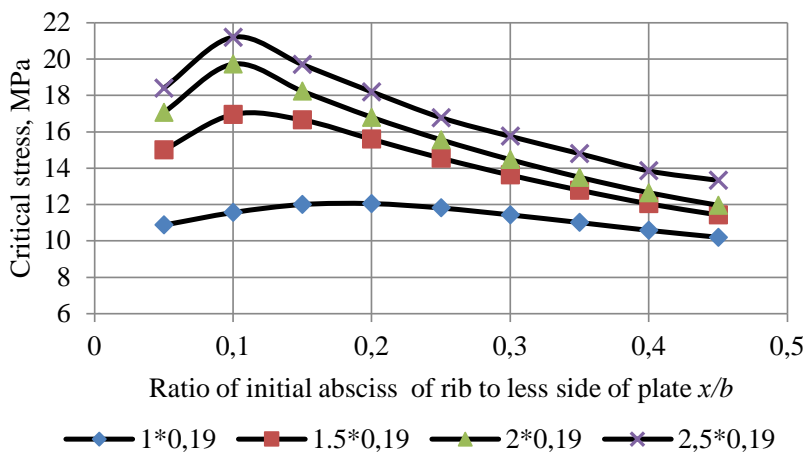

Fig. 6 Dependence of critical stress $\tau_{c r}$ on location of two inclined ribs in clamped plate $200 \times 100 \times 0.19 \mathrm{~mm}$

It is possible to appreciate efficiency of stiffeners from Fig. 7, which is constructed in dimensionless coordinates: along axis $O X$-ratio of height of rib $h$ to the plate thickness $t$, and along axis $O Y$ - ratio of critical stress of stiffened plate to critical stress of plane plate. Such approach allows understand growth of stability due to stiffeners and determine critical height of rib. Fig. 7 show that increasing of height of ribs from $13 t_{w}$ to $23 t_{w}$ lead to growth $\tau_{c r}$ only at $5 \%(3,19 / 3,05=1.05)$, i.e. $h_{c r} \approx 15.4 t_{w}$.

To increase height of rib bigger of $h_{c r}$ is not need. 


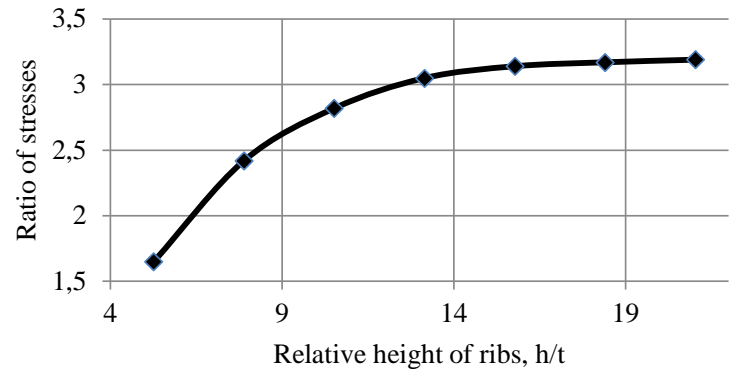

Fig. 7 Ratio of critical stresses of clamped rectangular plate $200 \times 100 \times 0.19 \mathrm{~mm}$ with two ribs to $7.01 \mathrm{MPa}$

After determination of critical rigidity of stiffener and more exactly its height, is important to appreciate value of critical stress of the stiffened plate. Using obtained by FEM results it is possible to note that under different thicknesses and consequently different slenderness of plate in diapason $167 \leq a / t_{w} \leq 500$ relation between critical stresses of clamped plate without stiffener $\tau_{c r}$ and critical stresses of stiffened plate $\tau_{c r}^{\text {stif }}$ there is very stable tie. It can be determined as:

$$
\tau_{c r}^{s t i f}=(3 \div 3.2) \tau_{c r}
$$

It can be seen from curve shown in Fig. 7.

Beside of clamped plate it was investigated buckling of simply supported rectangular plate with two stiffeners (Fig. 8).

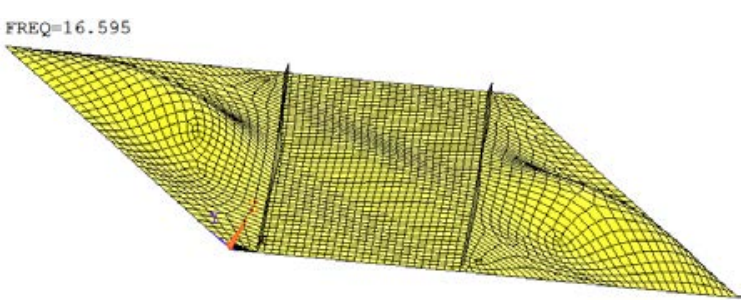

Fig. 8 Buckling of simply supported rectangular plate with two stiffeners $2.93 \times 0.19 \mathrm{~mm}$

Compare results of FEM performed for plates with different boundary conditions (Fig. 4, a and Fig. 8), it is possible to note that effect of stiffening for simply supported plate is bigger than for clamped one: for simply supported plate stiffener increase stability almost 3.7 times, but for clamped plate only 3.1 times. But absolute value $\tau_{c r}^{\text {stif }}$ for plates of the same dimensions for clamped plates is bigger than for simply supported one. Tie between critical stresses of stiffened plates with different boundary conditions can be approximately expressed as:

$$
\tau_{c r}^{\text {clamp }}=\tau_{c r}^{\text {sipm }} \cdot \sqrt{k_{\text {clamp }} / k_{\text {sipm }}}
$$

here $k_{\text {clamp }}$ and $k_{\text {sipm }}$ are coefficients in Eqs. (2) and (4) for critical stresses of plates with corresponding boundary conditions, i.e. $k_{\text {clamp }} \approx 10.38$, and $k_{\text {simple }} \approx 6.34$. For these values $\alpha=\sqrt{10.38 / 6.34}=1.28$ (compare relation $\tau_{c r}$ in Fig. 4 and Fig. 8). For stiffened plates with sizes $200 \times 100 \times 0.19 \mathrm{~mm}$ relation of values $\tau_{c r}^{\text {clamp }}=21.54 \mathrm{MPa}$ and $\tau_{c r}^{\text {simp }}=16.6 \mathrm{MPa}$ is equal 1.30. Difference between magnitudes 1.28 and 1.30 is about $1.4 \%$.

Beside of clamped plate with inclined ribs it was analyzed variants with two transversal ribs. Initially these ribs were installed at distance $0.25 a$ and $0.75 a$ from edge of plate, and later distance between them was variable. Results of calculations by FEM show the transverse ribs of the same dimensions increase stability in less degree than inclined ones. Under ribs of sizes $2.93 \times 0.19 \mathrm{~mm}$ critical stresses were equal 9.72 MPa (Fig. 9, a).

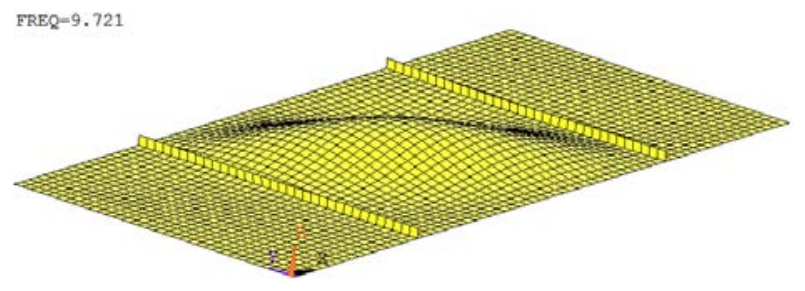

a

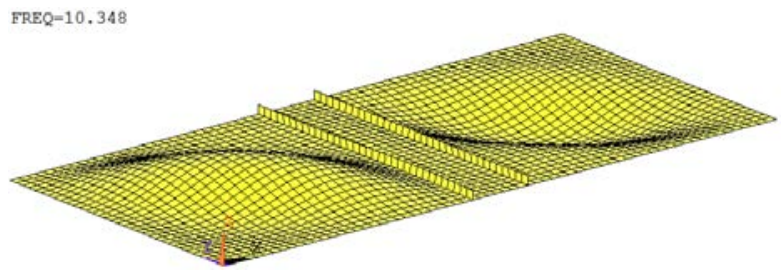

b

Fig. 9 Critical stress via distance between vertical stiffeners $2.93 \times 0.19 \mathrm{~mm}: \mathrm{a}-x=0.5 a$; $\mathrm{b}-x=0.1 a$

It is twice less then under inclined ribs. Vertical ribs under buckling remain straight, i.e. its critical rigidity is already reached. Reducing distance between ribs up to $0.3 a$ make possible to increase critical stresses almost 1.5 times, but further decreasing of distance between ribs bring down value of critical stress $\tau_{c r}$ again (Fig. 9, b).

After numerical investigation we consider now results of experiment performed by authors in laboratory POLEKS of Baltic State Academy for Fishing Fleet.

\section{Experimental investigation of critical stresses}

Although the calculations with FEM give true information about stability of the plate model, authors performed experimental investigation of the shear buckling of rectangular plate with and without stiffeners, because it is known "the practice is criteria of truth". In experiment it was checked up such factors, which is difficult to take into account in theoretical calculations: for example, dispersion of thicknesses on field of plate, existence of initial deflections, uneven distribution of loads along the edges of plate due to different tightening of bolts and so on.

Experiment was performed on specially designed installation (Fig. 10), formed of vertical pillar 1 fixed on massive basement. On upper end of pillar there is beam 2 with diverse arms, to one of ends of which is fixed tested specimen located in pinned quadrangular 4, joined to dynamometer 5 for measuring of applied load. To other end of beam is joined the tightening screw 3 , providing loading of specimen.

It was overall tested three clamped plates with sizes $200 \times 100 \times 0.19 \mathrm{~mm}$ without ribs and three stiffened 


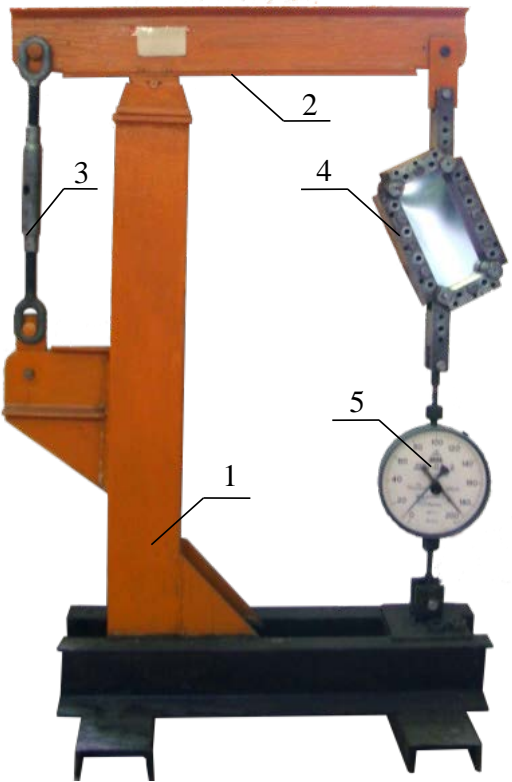

Fig.10 Installation for the shear plate testing

plates with ribs $6 \times 0.19 \mathrm{~mm}$. Material of specimen was steel C350. Binding of plate in quadrangular with help of bolts ensure their clamping in contour, and axial loading of quadrangular along diagonal, as it shown on scheme (Fig. 11, b) lead to shear of plate. As a result of performed tests of clamped plates with two stiffeners it was obtained an average value of critical load:

$$
P_{c r}^{e x p}=1.1 \mathrm{kN} \text {. }
$$
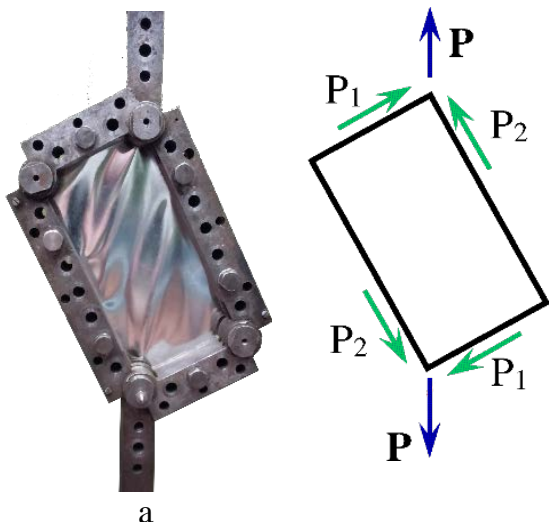

b

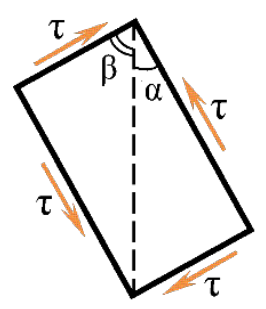

Fig. 11 Plate-specimen in pinned quadrangular (a), and scheme of distribution of forces along the edges of plate (b)

Recalculate value of critical load $P_{c r}$ into shear stresses is rather easy. Taking in a view scheme of loading (Fig. 11, b) it can be written:

$$
P_{c r}=P_{2} \cos \alpha+P_{1} \sin \alpha .
$$

Projection of forces at axis $O X$ gives:

$$
P_{2} \sin \alpha-P_{1} \cos \alpha=0 \text {. }
$$

For rectangular plate with $a=2 b$ value $\operatorname{tg} \alpha=0.5$ and $P_{1}=\tau_{c r} a t_{w}$ then from Eq. (21) we get $0.5 P_{2}=P_{1}$.

Substitution in Eq. (20) obtained values of forces
$P_{1}$ and $P_{2}$ allow to express $\tau_{c r}$ via $P_{c r}$ in form:

$$
\tau_{c r}=\frac{P_{c r}}{(\cos \alpha+0.5 \sin \alpha) a t_{w}} .
$$

In correspondence with Eq. (19) and Eq. (22) it is possible for plate $200 \times 100 \times 0.19 \mathrm{~mm}$ without ribs get:

$$
\tau_{c r}^{e x p}=\frac{1100}{(0.8962+0.5 \cdot 0.4481) 200 \cdot 0.19}=25.8 \mathrm{MPa} \text {. }
$$

Comparison of $\tau_{c r}^{\text {exp }}=25.8 \mathrm{MPa}$ obtained from test and $\tau_{c r}^{F E M}=21.9 \mathrm{MPa}$ received from calculations by FEM (Fig. 12) indicates that divergence is above 15\%. Such big difference can be explained with form and sizes of stiffeners, which have $L$-form and joined to plate with pointed welding. Small side of the corner rib was $4 \mathrm{~mm}$ and its height was $6 \mathrm{~mm}$. Thickness of rib was equal to plate thickness $t_{w}$. All that increase value of $P_{c r}$ significantly.

Beside of stiffened plates with two inclined ribs there were also tested plates without any ribs (Fig. 11, a). In this case critical loads measured in experiment $P_{c r}^{e x p}=0.302 \mathrm{kN}$ and calculated theoretically via Eq. (20) $P_{c r}^{\text {theor }}=0.298 \mathrm{kN}$ practically coincided. As it can be seen the divergence is near $1.3 \%$.

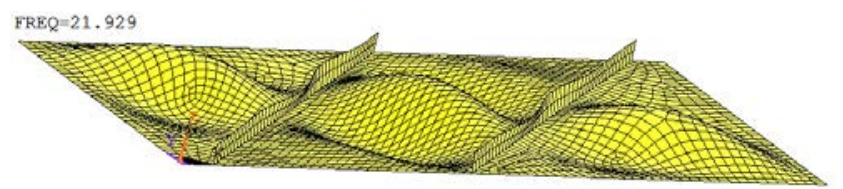

Fig. 12 Critical stress of clamped rectangular plate $200 \times 100 \times 0.19 \mathrm{~mm}$ with two stiffeners $6 \times 0.19 \mathrm{~mm}$

Completed investigations show effectiveness of the plate stiffening with inclined ribs which significantly increases stability of plate under shear. Results of these investigations can be used in estimation of load capacity of beams with slender web.

\section{Conclusions}

1. The inclined stiffeners are more efficient in arising of stability of rectangular plate than transverse one.

2. Existing recommendations of $\mathrm{SN} \& \mathrm{R}$ on reinforcement of plates are needed in correction.

3. Optimal sizes of rib for stiffened plate were obtained by authors in form (16) that is near to demands of Eurocode 3(9). All this is confirmed with calculations by FEM.

4. Experiments on finding of critical load performed on models of clamped rectangular plates $200 \times 100 \times 0.19 \mathrm{~mm}$ without ribs show satisfactory correspondence to theoretical values.

5. Installation of two inclined stiffeners can to arise the clamped plate stability almost 3.1 times.

6 . The increasing of the stiffener rigidity above critical is not lead to significant growth of $\tau_{c r}$, so as it remains almost straight during of plate buckling.

7. Field of application of Eq. (11) corresponds to values of the plate slenderness $\lambda_{w}>120$. 


\section{References}

1. Chen, W.F.; Lui,E.M. 2005. Handbook of structural engineering. Boca Raton: CRC Press.

2. Duggal, S.K. 2000. Design of steel structures. New Delhi: Tata McGraw-Hill Book Co.

3. Beg, D. 2008. Plate and box girder stiffener design in view of Eurocode 3: Part 1.5, 6th National Conference on Metal Structures 1: 286-303.

4. Hendy, C.R.; Presta, F. 2008. Transverse web stiffeners and shear moment inter action for steel plate girder bridges, Proceedings of the 7th International Symposium on Steel Bridges. Guimaracs.

5. Narayanan, R. 1983. Plated structures: stability and strength. London: Applied Science.

6. Bellur, Ravi S. 1999. Optimal design of stiffened plates. M.Sc. Thesis, University of Toronto, Graduate Department of Aerospace Science and Engineering.

7. Hasan, Mohammed M. 2007. Optimum design of stiffened square plates for longitudinal and square ribs, Al-Khwarizmi Engineering Journal 3(3): 13-30.

8. Leitch, Scott D. 1999. Steel Plate Girder Webs with Slender Intermediate Transverse Stiffeners. Ottawa: National Library of Canada. Bibliothèque nationale du. Canada.

9. Zoltan, V. 2004. Optimum design of stiffened plates for different load and shapes of ribs, Journal of Computational and Applied Mechanics 5(1): 165-179.

10. Kubiak, T. 2013. Static and Dynamic Buckling of Thin-Walled Plate Structures. Cham, Springer. 250p.

11. Akesson, B. 2007. Plate Buckling in Bridges and Other Structures. London, Taylor \& Francis. 282p.

12. Issa-El-Khoury, G. 2010. Optimization of longitudinal web stiffener location in horizontally curved plate girders: A Dissertation in Architectural Engineering. The Pennsylvania State University.

13. Aleksić, S.; Rogac, M.; Lucić, D. 2013. Analysis of locally loaded steel plate girders: Model for patch load resistance, Journal of Constructional Steel Research 89: 153-164.

14. Saliba, N.; Real, E.; Gardner, L. 2014. Shear design recommendations for stainless steel plate girders, Engineering Structures 59: 220-228.

15. Real, E.; Mirambell, E.; Estrada, I. 2007. Shear response of stainless steel plate girders, Engineering Structures 29: 1626-1640.
16. Chacón, R.; Mirambell, E.; Real, E. 2013. Transversally stiffened plate girders subjected to patch loading. Part 1. Preliminary study, Journal of Constructional Steel Research 80: 483-491.

17. Tang, K.H.; Evans H.R. 1984. Transverse stiffeners for plate girder webs - an experimental study, Journal of Constructional Steel Research 4(4): 253-280.

18. Birger, I.A.; Panovko, J.G. 1968. Strength, stability, oscillations. Moscow: Mashine Building, Vol.3. 567p.

19. Construction Requirements SP 16.13330.2011. Steel Structures. Revised edition of SN\&R II-23-81*. Ministry of Regional Development of Russia. Moscow, OAO «TsPP». 172p (in Russian).

20. EN 1993-1-5-2006. Eurocodes 3: Design of steel structures, Part 1.5: Plated structural elements. Brussels, European Committee for Standardization, 53p.

21. Pritykin, A.I. 2011. Elaboration of the calculation methods and design solutions for beams with single or twin row perforated web. Thesis. Dr. of Tech. Sci. Kaliningrad. 44p. (in Russian).

\section{A.I. Pritykin, I.E. Kirillov}

CRITICAL RIGIDITY OF STIFFENER FOR INCREASING SHEAR STABILITY OF RECTANGULAR PLATE

S u m mary

In plate girder with slender web the big transverse forces lead to web buckling produced with shear. One of the ways to increase stability of web near supports is to install stiffeners. In work the task of finding of critical stresses of clamped rectangular plate with installed inclined stiffener is considering. Investigations were performed with the finite element method and were checked with the experiment. Recommendations were given on choice of optimal size of stiffener.

Keywords: clamped rectangular plate, shear, buckling, finite element method, dimensions of stiffener, experiment.

Received January 04, 2015 Accepted March 15, 2015 